\title{
The importance of modernizing the specialty societies
}

\section{A IMPORTÂNCIA DA MODERNIZAÇÃO DAS SOCIEDADES DE ESPECIALIDADE}

JoÃo Carlos MaGI ${ }^{1}$

${ }^{1}$ Coloproctology Service, Heliópolis Hospital, São Paulo, SP, Brazil. Member of the Brazilian College of Surgeons and member of the Brazilian Society of Coloproctology, Rio de Janeiro, RJ, Brazil.

http://dx.doi.org/10.1590/1806-9282.61.01.021

Rapid advances in medicine occurred in parallel to the emergence of several specialties, which have been improving medical practice. The work of the specialty societies, therefore, alongside other medical organizations, is crucial for decision making in health care and to improve the quality of life of the Brazilian people.

The first specialty societies in Brazil were founded early in the $20^{\text {th }}$ century, when communication was difficult and scientific evolution, slower. Physicians from the countryside would attend congresses to learn the news. The pillars of the specialty societies consisted of classroom lectures during the congress and then articles written in journals and sent to members by mail. These were the main mechanisms for updating the medical practitioner at that time.

The influence of the medical profession - and other social groups - in government decisions and its role as a representative of society itself changed quickly, driven by new ways of communication and integration. Today, there are groups with strong arguments - and with "the right connections" - to influence government decisions in agreement with the law and applying ethical principles. Today, the internet keeps us updated in real time regarding new discoveries, giving voice to those who seek to participate in decisions. Today, it is possible to foster debate among experts in the subsections from the various regions of Brazil, valuing different points of view, in order to define protocol for action before the decision-making bodies. It is also possible to get financial support for institutions that train specialists, as well as to define action strategies together with other professional associations.

To maintain this role and achieve these goals, the specialty societies need to be improved. Thus, we believe changes are necessary, such as:
1. To rely on an outsourced legal department that can guide efficiently on behalf of the profession, according to the aspirations of experts.

2. To allow greater autonomy to subsections.

3. The top job in the specialty society, which is not the chairman of the congress, should be responsible for coordinating the management of the entity and its work before the decision-making bodies for the sake of the specialty. The position should be held for four years, with rotation of representatives. This figure should be appointed by each subsection, valuing the resources of the country's different regions, with headquarters located at the respective subsection and obeying a frequency based on the number of members in each subsection.

4. The position of chairman of the congress should be renewed annually, and the frequency with which a region is repeated should be decided in terms of number of members in the region's subsections. This person's responsibility is to organize the congress and its most important event, the General Assembly, attended by representatives of the specialty who discuss the main administrative and political matters. The congress must also enable information exchange among those attending on topics to be discussed at the General Assembly.

5. A technological communication department should exist, which enables meetings and quick and easy communication between subsections, and which provides easy access to news related to the specialty.

6. There must be transparency and easy access to the actions of the legal department and to the entity's expenses and bank accounts.

This is our collaboration to reflections on the subject. 